\title{
Sea and Ocean Generated Coral Made Nonreactive Dinner Sets for Creating Feel Good and Wellness
}

\author{
Yadav $\mathrm{RC}^{1 *}$ and Jaya Yadav ${ }^{2}$ \\ ${ }^{1}$ Water and Environment Interaction Specialist, India \\ ${ }^{2}$ Amity Business School, Amity University, Noida, Gautam Buddhanagar, NCR Delhi, India \\ *Corresponding author: Yadav RC, Water and Environment Interaction Specialist, India; Tel: 94123 01441; Email: ramcyadav@rediffmail.com
}

Received: October 18, 2020; Accepted: October 25, 2020; Published: November 10, 2020

\begin{abstract}
Food prepared for keeping feel good and wellness, thus ready for dining has ions which get quickly one to one neutralized or undesirably charged. Hence, use of non-reactive vessel for keeping prepared and ready for dining has to be kept in non-ionic non-reactive vessels is scientifically advisable for deriving full benefits of nutrition contained in meal prepared for breakfast, lunch and dinner. This research brings a new insight of food and health and use of non-reactive vessels, which will find scientific justification for vessels and discarding use of vessels made from different metals, particularly, most popular now prevalent a day's steel. The new non-reactive vessel is coral based in India. This emphasizes a justification of harnessing vast sea and marine areas for deriving coral form it with plentiful employment and market. The inland water bodies store long time deposited clays and silt which will find its new use in creating low cost such non-reactive vessels affordable by different groups of gentry and households. Thus, vast spread of ocean and marines can be explored for production and harnessing of coral for creating nonreactive vessels and generating employment and business. New innovative use of marine biology will get to benefiting all gentry and save pressure on earth. This research establishes that earth can sustain in creating still large opportunity for application of various innovative technologies.
\end{abstract}

Keywords: Food and nutrition, Feel good and wellness, Non-reactive vessels, Coral made dining vessels and dinner sets and sea and marine aquaculture

\section{Introduction}

After food is made ready it is prepared for eating by planning for serving in vessels, plate and bowls etc which take some time in completing family dining. In the storage time some vitamins Vit $\mathrm{C}$, Vit $\mathrm{D}, \mathrm{E}$ and $\mathrm{K}$ known not to get reduced in cooking will get ionically neutralised or changed, hence food quality gets impaired [1-5] Therefore, such vessels should be non-reactive to eliminate last minute loss in nutrition. Many potteries have been fabricating such vessels, but their use gets set back of social stigma of poverty. These days steel based utensils have taken stock of share on dining part as a result of non-breakable feature and ease of washing. There has been lack of scientific attention on this fact that almost 10-20\% of such ionic vitamins get lost or neutralized. The discrepancy in the vitamins cause hell of problems created to salt balance in the body maintaining homeostatic. These small shortfalls are not cared due to lack of scientific vision and people run after organic food. This is very reminding fact that even plants take their nutrition in ionic form so where is need of taking stand of organic food. In the earlier chapters organic seed spices were describe which can foster the taste of salt balance and micronutrients.

\section{Materials and Method}

\section{Earth and Ocean}

The planet Earth is a planet of oceans [6]. The total area of the Earth is approximately 510 million square kilometers and the oceans cover about 71 percent of the Earth's surface, which is about 360 million square kilometers. There are a total of 5 oceans, and they are the Arctic, Pacific, Atlantic, Indian, and the Antarctic Ocean. Out of these five, there are three major oceans, the Atlantic, Pacific, and the Indian Ocean. They account for 90 percent of the area covered by oceans. The Pacific Ocean is the largest of oceans, its area is 181 million square kilometers, which covers nearly a third of the Earth's surface. The Atlantic Ocean is the second largest, covering 94 million square kilometers, and the Indian Ocean is the third largest, covering about 74 million square kilometers. The oceans' tremendous presence causes it to have a huge effect on the planet and our civilization. It is greatly responsible for the climate of the Earth. It regulates air temperature and supplies moisture for rainfall. The ocean also provides us with food, energy, minerals, and a cheap method of transportation. Without the oceans, the Earth wouldn't be able to sustain life. The marine life have their preferred zone of habitation. The corals intensively grow in the oceans zones having slow waves and still water low depths and solar lights. The harnessing of costal sea such zone will bet revamped that will provide new material, product and employment and business which different from the marine fishery and shrimp harnessing. Thus development will make livelihood easy for people ling in the coastal areas.

\section{Nutrient Particularly Vitamins Which is Lost can be Saved to Create Health and Wellness}

Table 1 contains the ailment with development of vitamin deficiency lead to development of sickness of different degree of 
Table 1: Recommended daily dietary supplement of Vitamin adopted after Gupta [1].

\begin{tabular}{|c|c|c|c|c|c|}
\hline Vitamins & $\begin{array}{c}\begin{array}{c}\text { Units of } \\
\text { measurement }\end{array} \\
\end{array}$ & Men & $\begin{array}{l}\text { Pregnant and } \\
\text { lactating women }\end{array}$ & Ionic Change & Ailments affecting health \\
\hline & \multicolumn{5}{|l|}{ Mandatory } \\
\hline Vitamin A & $\mu$ & 5000 & 5000 & $+\mathrm{ve}$ & Immune functions, precarious lesions, (esophageal dysplasia, oral leukoplakia), cancer (breast) \\
\hline Vitamin D & $\mu$ & & 400 & & Osteoporosis, blood pressure \\
\hline Vitamin E & $\mu$ & 30 & 30 & + ve & Cataracts, Immune fractions, (Children, elderly) Cancer (lung, all) \\
\hline Vitamin C & $\mu$ & 60 & 60 & + ve & $\begin{array}{l}\text { Cardiovascular (mortality, platelet functions) Cataracts, Iron absorptionsCardiovascular (high } \\
\text { density lipo proteins, cholesterol, blood pressure, Peridontal disease, cold (symptoms). }\end{array}$ \\
\hline Folic acid & $\mathrm{mg}$ & 0.4 & 0.8 & -ve & $\begin{array}{l}\text { Immune function elderly, Birth defects,(neural tube defects, cleft lip/cleft) Precarious condition } \\
\text { (Cervical dysplasia, bronchial sinuous meta plasia in smokers) }\end{array}$ \\
\hline Thiamine & $\mathrm{mg}$ & 1.5 & 1.7 & & \multirow{5}{*}{$\begin{array}{l}\text { These vitamins get lost in pasteurization. Deficiency in such vitamins cause skeletal and mental } \\
\text { disorders. }\end{array}$} \\
\hline Riboflavin & $\mathrm{mg}$ & 1.7 & 2.0 & & \\
\hline Niacin & $\mathrm{mg}$ & 20.0 & 20.0 & & \\
\hline Vitamin $\mathrm{B}_{6}$ & $\mathrm{mg}$ & 2.00 & 2.50 & & \\
\hline \multirow[t]{2}{*}{ Vitamin $B_{12}$} & $\mu g$ & 6.0 & 8.0 & & \\
\hline & \multicolumn{5}{|l|}{ Optional } \\
\hline Vitamin D & $\mu$ & & 400 & & Osteoporosis, blood pressure \\
\hline Biotin & $\mu g$ & & 0.300 & Not known & Not clear \\
\hline Pantothenic acid & $\mathrm{mg}$ & -ve & 10.0 & -ve & Similar to Vit C \\
\hline
\end{tabular}

severeness. As such it may appear a simple fact but one can imagine its adverse or bad effect when one gets sick. Therefore, when it is known to happen, one is out to take all necessary precautions. This fulfils the legendary saying that prevention is better than cure. In exercising such prevention this book provides basic information, which should be adopted right from the time from when one comes to know.. The last columns of Table 1 provides long list. As an example a cursory review of the deficiency of vitamins leads to development of cancers of varying types, which is highly fatal and its treatments become unaffordable under many house hold and economic situations. This example serves that use of non-reactive vessels be made, particularly plate used for breakfast, lunch and dinner. It is necessary to keep in mind that milk is to be eaten and not be drink in its liquid form. Hence, use of nonreactive plate is highly scientifically advisable. In time when science was not known it would have been subject of awkward talks. But, now time has come, as created by this study that non-reactive vessels should be adopted for eating the meal of any event in all situation. When it comes to any feast of large gathering, it had been only plant leaf made unformed plates, viz. banana leaves and any wide leaf. This is evident that this situation has changed world over. This needs change for entire globe. The reduction in loss of vitamins will reduce such losses in provitamins and at the same time reduction in incidences of sufferings due to disease. Any one suffering will feel good and have some ease in difficult life (Table 1).

The vitamins get reduced by ionic change caused by metallic vessels. Reductions in vitamins have already occurred during cooking. Hence, any further, reduction is highly undesirable, which had not caught attention of public, in general. Although food has been getting eaten after six months of age onward one has not imagined that in one's life time how much total vitamins have got lost. The losses in such vitamins have been giving way to different ailments and discomforts and rise in medical bills. There have been many ailments which have been given undue genetic cause. This is a tragedy of knowledge gap, hence people remained susceptible to suffer from diseases. Therefore, when scientific wisdom has come up it is highly justifiable to use nonreactive vessel for dining and derive good effects in terms of feel good and wellness.

\section{Collection of Necessary Information in Preparation of the Manuscript}

This author has been writing research on food and nutrition since 2014. He has brought several innovations on linking sea and marine for harvesting organic nitrogen, organic phosphoruss and has been contuing his endeavours towards bringing feel good and wellness. He has combined his research in the form of a book [5]. He again innovated his scientific attention on finding way how to save loss of vitamins which cause lot of ailments. In this new aspect of creating nonreactive vessel was devised. Thus scientific effort has culminated in this innovative article.

\section{Results}

\section{Liability of Loss of Vitamins from Foods}

There are various stages where vitamins get lost [1]. The vitamins soluble in water, particularly vitamins $\mathrm{B}$ complex, vit $\mathrm{C}$ and folic acid etc get de- ionized (Table 1). Among several diseases cancer is caused in one form or the other when there is vitamin deficiencies. Hence, saving in such vitamins will create lot of meaning of good health and wellness.

\section{Essential Types of Non-Reactive Vessels}

There have been lack of awareness of knowledge on the loss of vitamins, hence consideration on selection of vessels specially for keeping cooked meal and dining had not been selected on the bases 
of avoidance. The consideration of ease of cleaning, non-breakable and longevity of its rough uses have been the main consideration. The ailments due to loss in vitamins had not come up in imagination then. Now stage has been coming when such vitamin losses can be easily avoided where feel good and wellness is getting priority. Therefore, use of non-reactive vessels and dining set will be picking up with time. In this direction some non-reactive vessels had been brought in use, but it had no scientific backing. As now scientific backing is very strong and demanding saving loss of vitamins. The saving in loss of vitamins when its kept ready for dining, during dining as well as, when cooked meal is kept for next meal, lot of saving can be acquired. It is difficult to show physically the saving, but feel good, wellness and freedom from diseases will become index for gauging impact of such saving from the vitamin losses. These good developments will eliminate the many mis believes on ailments and disorders in physical and mental health. Reports already exist that one of every seventh person suffers from the mental disorders, implicating discrepancy of vitamin thiamin (B1) $[1,4,7]$ Indian Council of Medical Research reported that one of every seven Indians are affected by mental disorders. Ladies in particular suffer mental bad effects due to food and nutritional discrepancy.

\section{The Non-Reactive Vessels and Dining Sets}

\section{Coral Based Vessels}

Most useable common vessels are eating bowls, and plates. It will not be out of context that even spoons should be also made from non-reactive vessel. Some innovative vessels are being prepared from agricultural residue. Some ideal non-reactive vessels are included here to exemplify the facts brought out here.

\section{Clay Material Based Manufactured Crockry}

Different sets of ideal non-reactive low cost vessels useable for dining (Figures 1a and 1b).

\section{Social Implications and Fostering Elimination of Neutralization Adverse Effect by Giving Gift of Non-Reactive Vessels}

Once beginning is made with scientific reason and justification people will adopt this new vessel, which will pay dividends in due course of time, first by reduction of medical bill, keeping feel good and wellness. It is also elaborated in the book that the adequate vitamin will enable produce health and mentally sound offspings. Therefore, in order to enable this thing to happen a social culture blessing is enforced. In this social welfare all guests to the married couples should be given nonreactive coral made vessels. The gifted item will be highly useful for the recover for use for eating meals and keeping remaining food for the next time consumption. This fact and resulting development will sweep lot of ailments occurring due to deficiency in vitamins. It is visioned that lot of progress will be made in use of non-reactive vessels it is lot of precious resource would get saved which will come for welfare of community.

\section{Generation of Basic Material from Marines}

The globe is occupied by marine and sea even more than two third of surface. This vast resources must have been utilized in ways one might think in isolation for fishing and sea product. This chapter focuses that vast sea resource should be harnessed for use for fostering
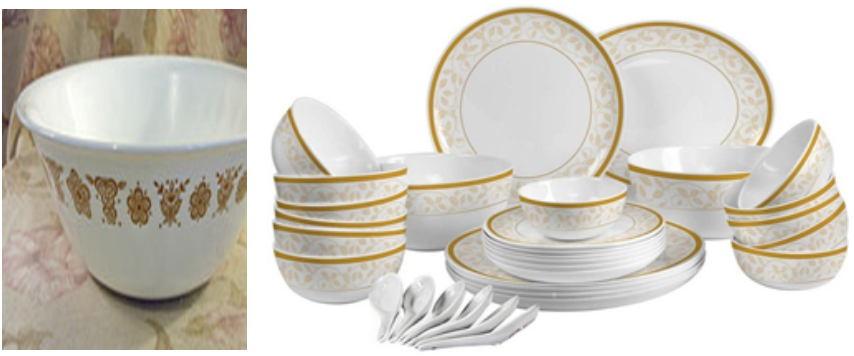

A non reactive bowl for breakfast

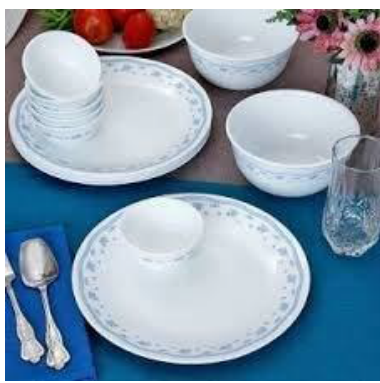

Dinner set of plates
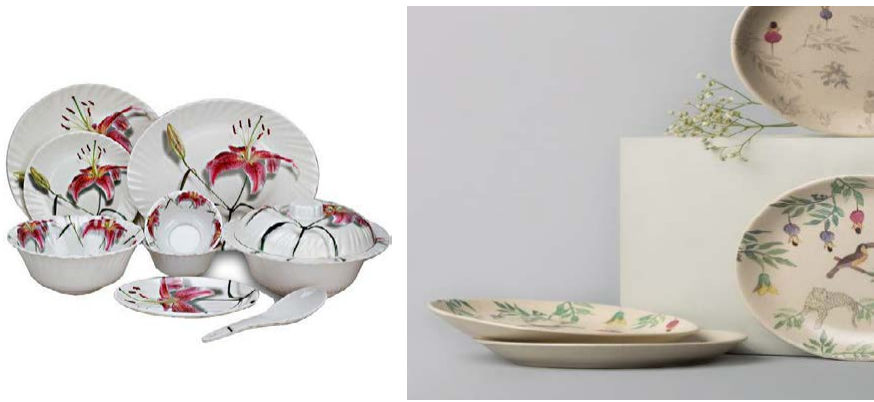

Decorative non reactive dinner set

Figure 1a: Different sets of ideal non reactive coral vessels useable for dining.

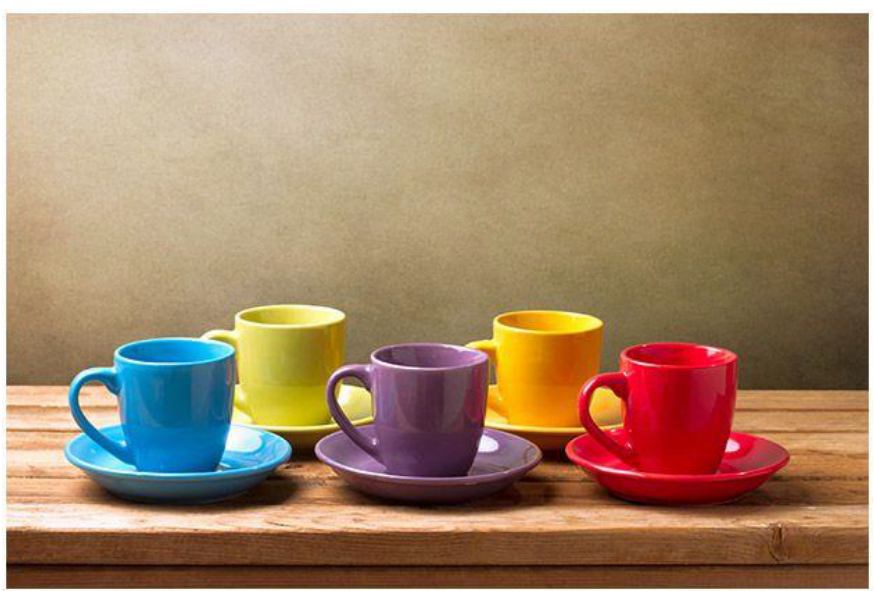

Non reactive tea and snack plates

Figure 1b: Different sets of ideal non reactive low cost vessels useable for dining

growth of coral, which will enable sufficient raw materials to be used in preparation of non-reactive vessels as brought under section 3.2 and 3.3. This new window will create employment and resources for the world and marketable semi durable vessels. This is a wonderful development. Although some processes are known, when world eyes 
look at the avenue some simple method of processing will come in use. Therefore, beginning made in this study will grow to become trees to provide prosperity in the global health (Figure 2).

\section{Utility of Clay Siltation Depositions in Water Bodies}

Soil formation and erosion are earth surface processes which are highly variable. Countries have developed water conservation dam reservoirs under multipurpose projects viz irrigation, flood control, electricity generation and fisheries etc. The catchment areas have always been attempted with soil conservation measures in upland areas and silt detention structures to reduce siltation and save loss in water storage capacities. However, in spite of any level of efforts, the fine sediments viz clay and silt cannot be completely checked, meaning thereby large accumulation of clay it is silt deposit in such water bodies. This valuable deposits accumulating in water storage bodies, remained as a problem causing loss in storage capacity only, but it could not come to imaginations that these deposits could be extracted and economically utilized for making value added products and endless efforts have been made with expenditure of huge budget. Thus, this research is bringing new scientific vision in the present study that such clay and silt may be useable in preparation of pottery which will serve as nonreactive vessel. The utility of such non-reactive dinner sets have already been brought out in sectinns 3.3 and 3.4.
Thus, this dual benefit will create new work opportunity for the local people. Government of India had created Mahatma Gandhi National Rural Employment Guarantee Act (MNREGA) initiated in 2005, remain at the brink of existence. This act provides rural employment for 100 days work mostly in digging and excating earth in pond and allied water bodies. There has been nothing scientific advancementit remained mere social promoting scheme, which have been suffering of pros and conse with the change of governments. This innovative and ideal creates use of such materials will become new solution and making it very effective in using resource, creating employment generation and beneficial employment guarantee scheme under the MNREGA, which have been renamed at conveniences. There has been lot of political debates on the MNREGA but nothing scientific vision could emerge. Derivation of such silt and clay materials will be useable and silting water bodies will get ready for runoff water storage in the rainy season, which create ground water recharge and supplementary irrigation during intermittent droughts and safeguard country from adversities of climate change.

\section{Enterprise of Manufacture of Non-Reactive Vessels and Coral Based Dinner Sets}

The clay and silt deposits have been used in making earthen small pot by earth potter and to some extent in making clay based crockery.
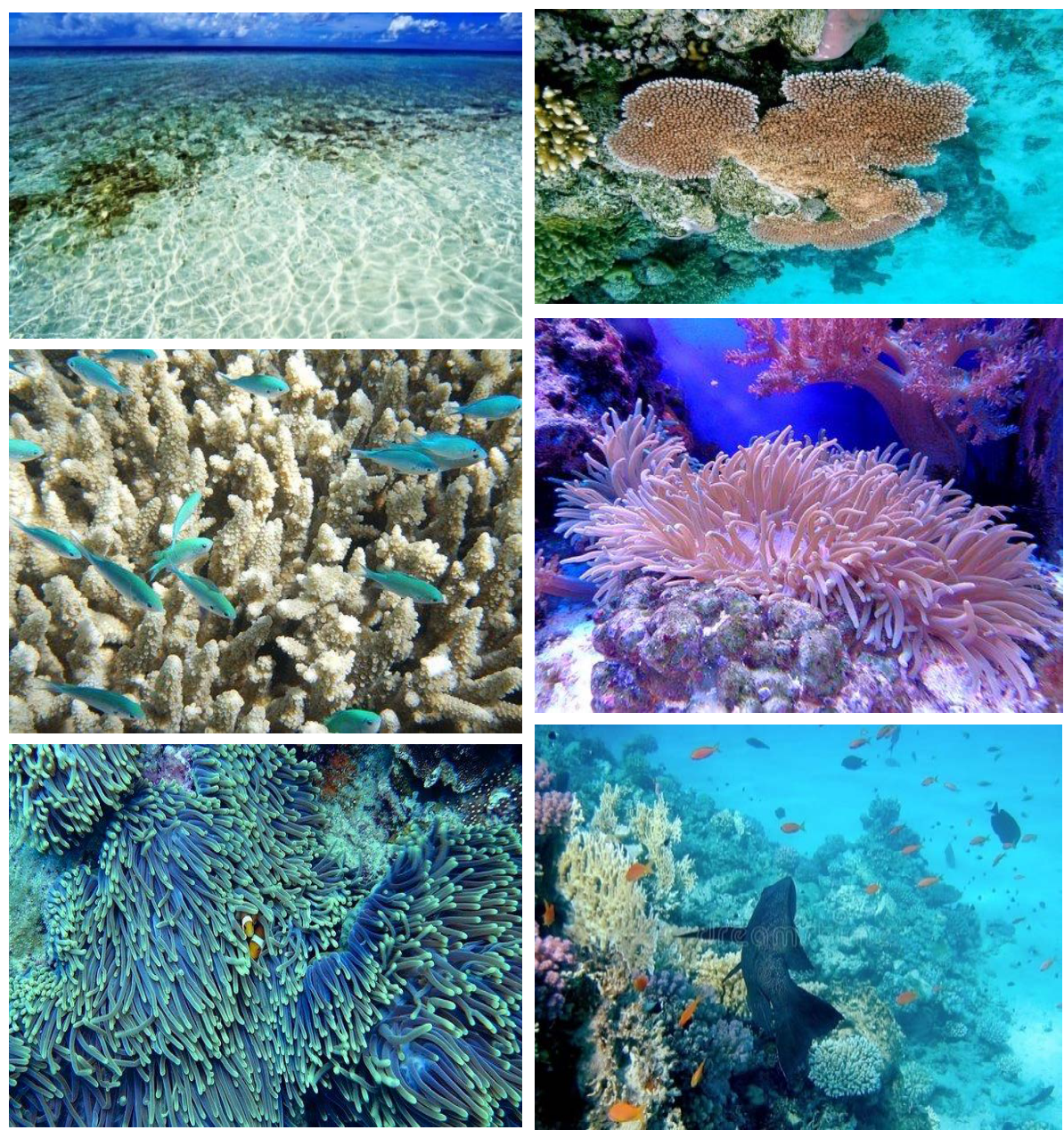

Figure 2: Coral from marines. 
Such ventures have been rather on traditional fashion and had no scientific backing. This research is giving scientific backing which will ease and improve feel good and wellness of people. Therefore, the dying system will get revamped to create employment and business. The new material will be useable for coral based dinner sets, whereas clay derived from the water bodies will produce low cost vessels for public in general.

A functional unit of creating such produce is developed based on example cited in reference, Horobin [8]. The diagrammatic figure explains provision of selected material mixing tank, fine grinding by burr mill, wet grinding tank, filtration unit and again mixing to bring consistency required from needing and molding as well as slip casting of utilities of required shape and sizes. The prepared vessels are fired at first stage of cooking at $1650{ }^{\circ} \mathrm{F}$ for which very high rise chimneys are constructed which emit large volume of $\mathrm{CO}$, causing air pollutions and suffer restriction from pollution control board. A new innovative kiln has been developed to capture and recirculate the smoke and reuse for burning that will eliminate air pollution and enhance fuel use efficiency. Its low height will make low cost and easily manoeuverable. The temperature manouuvre can be carried out by electronic based controllers. Thus, the scientific kiln will permit large scale multiplication and use.

The vessels so prepared are again polished which carried out I as second firing which is at $2370^{\circ} \mathrm{F}$, which can be carried out in the large size such facility. This innovative ideal development needs guided fabrication of the facility (Figure 3).

\section{Geographical Registry in Sea and Marine Material and Products Processing Resulting Quality Product}

When sea produce coral made material use dinner set are used the quality will be different which can be given unique geographical registry number (GIr) [9]. Similar quality differences may appear for the material produced from clay based pottery and crockery for their quality by same GIr. Such standards will establish uniqueness in the product and it will fortify business and confidence in the buyers. This identification will attract international market reputation.

\section{Linking of Ocean, Coral, Fishery, Bird, Pottery Industry, Agriculture, Human and Environment}

This new process and products will come in use to produce employment and prosperity, business of marketing and sale. This new innovative module will have different segments and lot of employment opportunities. This is an ideal venture for consideration under the startup projects. The entire end result will lead to development of new science backed venture and produce exact anticipated and certain results. The earlier innovative researches have created method for harvesting of organic nitrogen $(\mathrm{N})[10]$ and phosphorus $(\mathrm{P})$ [11]. Birds eat the fish from water bodies and dropping, which is called as guano becomes harvestable and refined to make various uses. Likewise the coral can be harnessed for preparing for coral based dinner set of attractive designs. The vast ocean resources have not come in imagination and this innovation will create new opportunity of employment, water fishery, birds, environment and human. This new linkage will be very prosperous. Thus, these researches open new world opportunity.
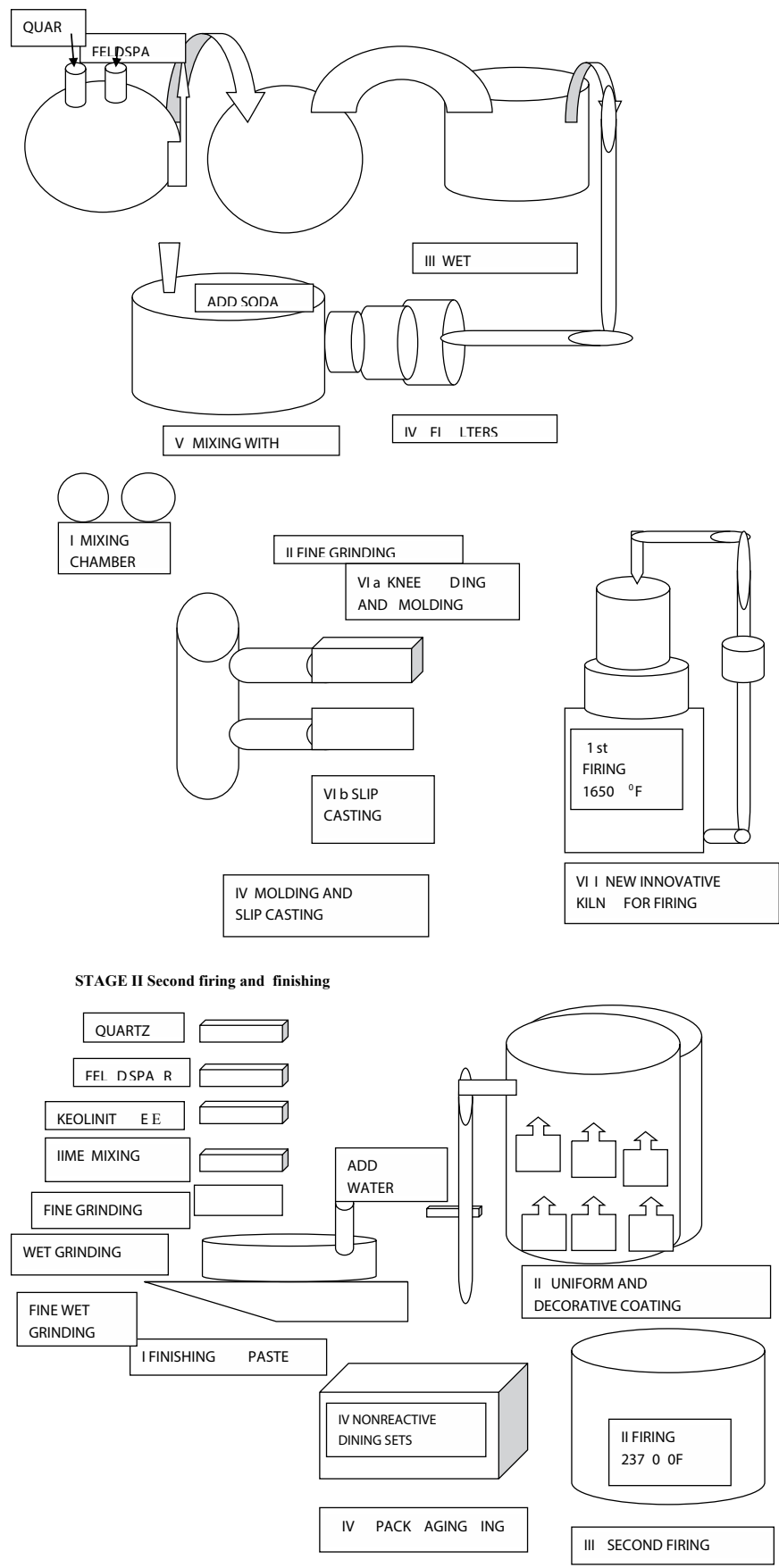

Figure 3: Functional units of organizing coral based industrial production unit for producing nonreactive coral vessels.

\section{Discussion}

\section{New Opportunity of Eliminating Wastage of Precious Vitamins}

As presented in Table 1 lot of finished food ready for eating has been getting de ionised and neutralized one to one [12-14]. The corresponding ailments occurring due to deficiency of corresponding ailments fully justify elimination of such undue losses. Thus, this research created a new opportunity for eliminating wastage of precious invisualised wealth. 


\section{Creation of New Resource}

The vitamin's losses have been occurring since ages and lot of wealth had been going to drains due to lack of knowledge and wisdoms and lot of ailments and medical expenses are adding to undue suffering of the people. The article is creating full justification for saving of such invisualised wealth and bringing them to creating awareness in the public. There have been many researches on exploitation of ocean and marines including marine fisheries, but it did not get adequate scientific backing, hence use of coral had been in a weak stage of development. This research has provided adequate scientific backing for in justification of coral vessels as nonreactive dining sets. The $71 \%$ of earth areas are occupied but ocean and marines with vast length of shores with shallow water. There are some specific areas where corals thrive and grow. The coral growth can be harnessed for promoting such vessels.

The clay and silt deposits in the inland water bodies can be equaly well utilized in creating such vessels affordable low cost purchasing. These types of vessels also lead to same end levels in saving loss of such unforeseen wealth. Thus, this innovative research has created new precious resource and method of retrieving as well as conserving by use of non-reactive vessels for both high profile prosperous gentry as well as low investing gentry.

\section{Extending Utility and Scope of Harnessing Useful Products from Sea and Marine}

Use of coral obtainable from some specific coral belts have begun making such products, thus, it is not a new claim of product being made in this research. What had been going on in this direction is in weak stage due to lack of scientific backing. This research has created new and adequate scientific backing with full justification of convincing people to adopt the non-reactive vessels for storage of cooked food and for dining is new thrust. Thus, this research creates strong business, markets for feel good and wellness and wealth using resource from vast ocean and marines. There had always been provocation of limited land fresh water throughout the world, but there had been any new innovation to make still better use of vast sea and marine resource. This research has created wow innovation for benefitting global as well local gentry by using product, which is not limited by quality of water requirement of land and even a nondispensible use of sea water. Whatever have been going on or might come in future, remains equally open for future developments. This research is not limited by any constraints of climate change, budget involvement and any defeat of any ongoing research.

The development of crockery from clay and silt is equally in that direction. The earlier efforts on soil conservation of soil loss remain in sufficient in arresting such fine particle pollutants and get deposited in transition. Such deposited materials can be annually scrapped from such water bodies and brought to effective use, thus this action will restore storage capacities of inland water bodies, which will enhance ground water recharge and its use during intermittent droughts for supplementary irrigation. Thus, this research is going to change life of global gentry in its own function without worrying about it and getting to realization in due course of use and change in social behaviour.

\section{New Use of Long Term Deposited Clay and Silt in Inland Water Bodies}

NAREGA has been suffering from lack of technological linking of water use hence it is subjected to lot of sociopolitical debates [14]. New use of material will create new opportunity, for employment generation and deriving such unimagined feel good and health wellness, in addition creating an auto-function in creating storage facility that will create resilience during climate change and aberrations of rain events leading to intermittent droughts season. Thus, this research is creating new resilience under the changing climate, where politicians have been feeling very happy in development of unsuitable and un effective measures.

\section{Innovations in Manufacturing Process of Non-Reactive Vessel}

The process of manufacturing storage and dining set is drawn on line of highly known and well documented record [8]. The component operational units are collection of geological base materials viz quartz and feldspar, which might be existing and placed in mixing tank in equal proportion. The next operation is fine grinding of the base mixed materials, followed by wet grinding. The wet grounded fine material is passed through multistage filtration unit. The filtered material is brought to workable consistency so that material is kneaded and casted in to mold or slip casted. The dried material is separated from their mold/castings and stked in a firing kiln for firing at $1650^{\circ} \mathrm{F}$ for reasonable duration of 7-10 days.

The selected half burnt prepared vessels are coated once again for the second time with materials prepared in second lot and grounded dry followed by wet fine grinding (Figure 3 ). The new paste is coated on all vessels in similar manner and with additional decorative designs. The entire vessel lots are staked in high temperature range and burnt at still higher temperature at $2370{ }^{\circ} \mathrm{F}$. These two controlled temperature burning completes process of manufacturing of the non-reactive vessels.

The village artisans making earthen pots do not add quartz, hence their pots remain largely red and temperature is also not so high. The quantity of quartz is deciding factor of quality of crockery, addition of soda and lime and burning at high temperature converts product in almost white colour.

Second firing and polishing mate the product tough and still brighter in colour. There are variations in qualities and cost increases with completion and perfection of burning.

The unit operations are almost patternised and use of machineries for various operations may vary from plant to plant depending on preference, ease of operation, performance efficiency and cost of machineries. The ratio of mixture of quartz and feldspar will have deciding command on quality. Next operation is firing in kilns, Conventional kilns have high chimney which is costly and emit large volume smokes, which cause air pollution and suffer set back of regulatory restrictions on height of chimney. In the present study an innovative no smoke releasing low height kiln was developed which involves low height and it becomes easy in operations and maintenance. The new kiln will consume low volume of fuel and the fuel will get converted in to biochar, which will become source for carbon useable in agriculture. The enhancement in bio-char will 
increase $\mathrm{C} / \mathrm{N}$ ratio that will enhance productivity of agriculture. Thus, cause of sea derived operational process produces usable biochar for agriculture and food production. Such links have not been existing and this chain will be synchronizing one being input for the other. The irrotaional operation of system will induce sustainability in agriculture. These developments require research endevours for refining the operational parameters to produce quality product of coral, clay based crockery. This research has set module of process and inspired following generations to optimize and further refine it.

\section{New Vast Resource of Creating Startup Projects for Employment Generation and Supporting House Hold}

The new vast resource and innovative technology and tremendous beneficial impact innovation creates new opportunity for new startup project. This area needs special attention and crating new initiative for second generation of employment, for which MNREGA was launched. This research creates new resource which has evolved from previous programmes. This will add new vigour to ongoing programme as well as new intutitaive in creating employment opportunity for justification of bringing for effective public governance.

\section{Enhancement of Resource Opportunity of Planet Earth and Reducing Pressure on Limited Terrestrial Ecosystems}

The planet earth has been occupied by vast are under sea and marines. The limited terrestrial are have been going under stress. The present research makes use of natural resource, which have been existing and bringing in strong stream proceed vitamins get lost. The conservation of such vitamins will make still better use of stressfully resources. The linkage between sea and marine, fishery, birds, agriculture human and environment have already developed in deriving organic nitrogen $(\mathrm{N})[11,15]$, which was recognized in global assessment and declared winner of world Academic Championship in Biological Sciences in 2018 and phosphorus (P) [12]. This research demonstrates new opportunity creating innovative method not limited by any aspect and any corner. The marine biological product and clay deposits in inland water bodies are new addition in deriving useable non-conventional products.

\section{New Geologic and Geographic Resources Avenue}

This research is not limited by any geographical and geologic limitations. Depending on water depths, situation of sea wave still condition the coral reaf are primarily developing at Andman sea shore between two hills viz Andmon city and Ross Island, where it is shown by boat operators in touristic visits and becoming source of recreation. Such plentiful situations are existing where corals are developing (Figure 2). In any case use of coral is not limited by any such restrictions. The business related to coral will flourish with global increase in population [16] and increase in Indian population [17]. Earlier sections have enlightened various aspects of this wow innovation.

\section{Climate Change Will Not Affect Sustainability of Resources Harnessing}

Lot of vices have been raise in revealing adverse impact of climate change on coral reef. What have been going it the least impact of climate change. Different aspects have already brought in creating such resilience in terrestrial eco system. The vast area of ocean and marines will be benefiting and producing the profuse growth of coral. The coral will be useable in creating high value vessels which will become source of promoting international business. The global gentry will derive benefits in terms of feel good and wellness from use of coral vessel as it will stay for long doing good, hence creating sustainably increasing business and employment opportunities.

\section{Relevance, Effect, Efficiency and Impact and Sustainability}

This research is highly relevant as it is related to food and health which is priority of human needs, it is creating impact, it is highly effective in eliminating loss of vitamins. It involves change in one to one chemical change ions, impact of change in quality of life which will come to realization after some days of use. It is highly sustainable as it is going to function in irrotational rotation [15]. This research is most innovative that will change daily life of the global people.

\section{Opportunity of Vast Natural Resource Harvestable for Human Welfare}

This research has brought new natural resource derivable from vast resources as well as inland water bodies to save loss of unimagined tremendous important wealth. This surpasses any natural resources so far managed and created new resource, method and process which will utilize both the types of materials and produce quality product. This will create tremendous employment. The new natural resource is derived from the planet earth and also reducing stress of terrestrial ecosystem. Thus, this is a real and true way of sccomplishment of the earth care. Such earth care have not come to imagination and countries have been trying to explore new planets. The Earth wonderful planet can be further sufficiently brought to new uses viz non-dispensible use of water, not demanding any terrestrial land for production and may other important features brought out earlier.

\section{Strength, Weakness, Opportunity and Threat (SWOT) Analysis}

SWOT analysis revealed going in strong favour of strength as it is scientifically backed. It is free from any weakness as nothing is causing it to be fond bringing adverse impact but in this research new avenues have been created. The study set way to draws resources from earth's vast resource sea and marine as well as terrestrial water bodies, hence it is creating tremendous unforeseen resource, creating reduction of precious vitamin wealth, getting to drains and creating opportunity of employment to the extent that it can be extended to any level. There is no threat, rather people will come to realization of impact on feel good and wellness and saving in medical bills.

\section{Conclusions}

This new research on the cause of deficiency in vitamin which occurs due to ionic change of food made after having gone for investment, reduce loss and avoid occurrence of non-bearable ailments and diseases. This will save large volume of finished vitamins, which will get in use in its auto function, which has been going to waste water streams. This may appear as an airy thought, but all things 
have been derived based on scientific facts. The vast ocean will create new opportunity for world to flourish and make use of resources in still better way than what has been going on. This will transform world population healthy, brainy and efficient working.

\section{References}

1. Gupta US (1992) Crop improvement quality characters. Science Publishers Inc Enfield New Hampshire 3: 037480.

2. Hui cited in Gpta [1] (1992)

3. Yadav RC, Yadav J (2018) Innovative biotechnology for production to consumption for promoting new theme of health care-food is medicine, Madrid Spain.

4. Yadav RC (2020) Eating milk is better than drinking. Paper accepted for presentation at 6th global congress on food and beverages, Dubai.

5. Yadav RC, Yadav UR (2019) Innovative scientific management of milk-dairy-foodhealth fodder-waste and environment. Under publication. Oxford Scholar Publishing co. London.

6. $\quad$ Eric Cheng, "Down loaded from internet”, 1997.

7. Hindustan (Hindi) (2019) Daily news Paper, Chintajanak: saat me se ek bhartiya mansik rog se grast Worry: One of every seven Indians are affected by mental ailments. Hindustan Hindj, New Delhi.

8. Bandy, Horbin, “China clay-porcelain. Science and technology, How it works. 4: 465-461.
9. Guftafson AE (2010) "Hand Book of Fertilisers, Their sources, make, effect and use", Third edition, Agro Bios, Jodhpur, India.

10. Yadav RC, Yadasv J (2013) Development of business out sourcing (BPO) in agriculture for sustainable productivity and environment protection.ijmsem. Taylor and Francis London.

11. Yadav RC (2014) Biological nitrogen harvesting from acquatic eco systems: A new scientific vision. Fish and Aqua culture Journal.

12. Yadav RC (2015) Biological phosphorus harvesting for multiple uses-A new scientific vision. J Aqua Culture and Marine Biology 2: 2.

13. Yadav RC (2015) Geology and geographical implications on food related health hazards. And their remedial measures in 8th WSE A conference on geology and geography. Celerno university, Italy.

14. Hindustan (Hindi)." Manrega majdori pandrah din me nahi dene par muwabja (Delay in payment of wage at every 15 days will be compensated. Hindustan, Delhi, Dec 25, 2019 pp 8

15. Ramamrutham S (2008) Hydraulics, Fluid Mechanics, and Hydraulic Machines. Dhanpat Rai Publishing Co., New Delhi, 110002, Eigth Edition

16. S Thompson, Warren and Tony Evan, Baver, Population Problem, McGraw Hill. New York, pp (1965)304

17. Carolin, Thomas, Evans T (2011) Poverty Development and Hunger: In Balis John Srev, Smith and Patrics Ovan (Eds) Globalization of world politics-An introduction to waorld relation. Oxford University Press.

\section{Citation:}

Yadav RC, Yadav J (2020) Sea and Ocean Generated Coral Made Nonreactive Dinner Sets for Creating Feel Good and Wellness. Aquac Fish Stud Volume 2(2): 1-8. 